\title{
Die \\ rheinische liberale Presse im Jahre 1859
}

\author{
Inaugural-Dissertation \\ zur
}

\section{Erlangung der Doktorwürde}

genehmigt

von der Philosophischen Fakultät ·

der

Rheinischen Friedrich-Wilhelms-Universität

zu Bonn.

Von

Karl Heinrich Grosse-Freese

aus Versmold (in Westfalen).

Promoviert am 31. Juli 1914.

\section{Bonn 1914}

A. Marcus \& E. Webers Verlag Dr. jur. Albert Ahn 
Berichterstatter:

Geheimer Regierungsrat Professor Dr. A. Schulte.

Mit Genehmigung der Fakultät kommt hier nur Kap. 5 der eingereichten Arbeit zum Abdruck. Die ganze Arbeit wird unter dem Titel: „Beiträge zur Charakteristik der öffentlichen Meinung in der Rheinprovinz im Jahre 1859" erscheinen. Heft 11 der „Studien zur rheinischen Geschichte ${ }^{a}$, Bonn 1914. 